\title{
Lugares de memoria en Andalucía. Un camino por recorrer
}

\author{
Andaluziako memoria-lekuak. Egiteko dagoen bidea \\ Sites of Memory in Andalusia. A way to go
}

\author{
Eduardo Barrera Becerra \\ Abogado. Universidad de Sevilla \\ ebarbec@gmail.com \\ Fco. Javier Giráldez Díaz" \\ Doctor en Historia Contemporánea. Universidad de Sevilla \\ giraldez2009@gmail.com
}

\author{
Miǵuel Ánǵel Melero Varǵas* \\ Doctor en Historia Contemporánea. Universidad de Málaga \\ melerovargas@hotmail.com
}

Recibido / Noiz jaso den: 29/05/2020

Aceptado / Noiz onartu den: 29/06/2020

\section{Resumen}

El texto pretende realizar un acercamiento a las actuaciones relacionadas con la gestión pública de los lugares de memoria de la Guerra Civil y el franquismo en Andalucía. En primer lugar, se repasa sucintamente la realidad represiva que implementó el franquismo en la región con más víctimas de España y que dio lugar a una serie de espacios relacionados con la memoria de las víctimas. Para ello se examina la normativa específica que los ha regulado en Andalucía y que ha sido referente para otras regiones con base a la cual han sido declarados oficialmente por parte de la Junta de Andalucía cincuenta y cuatro lugares de memoria. La importancia de estos lugares, su heterogeneidad y ejemplos significativos son objeto también de este artículo realizado desde la experiencia en la elaboración de las normas y gestión de estos espacios de sus autores en la extinta Dirección General de Memoria Democrática de la Junta de Andalucía.

\section{Palabras clave}

Lugares; memoria; víctimas; represión; Andalucía.

\section{Sumario}

1. INTRODUCCIÓN. 2. LOS CIMIENTOS de los lugARES dE MEMORIA EN ANDALUCÍA. 3. ANDALUCíA: COORDENAdAS PARA LA MEMORIA HISTÓRICA. 4. REFORZAMIENTO NORMATIVO DE LOS LUGARES DE MEMORIA Democrática. 5. Conclusiones. Bibliografía.

* Fco. Javier Giráldez ha ocupado el cargo de director general de Memoria Democrática de la Junta de Andalucía entre los años 2015 y 2019, el mismo tiempo en que Miguel Ángel Melero ha ocupado, en la misma unidad, el de asesor para la Memoria Histórica y coordinador de Exhumaciones de la Junta de Andalucía. Eduardo Barrera ha sido asesor en asuntos jurídicos de la misma Dirección General entre 2017 y 2019, siendo actualmente asesor del Secretario de Estado de Memoria Democrática en el Ministerio de Presidencia, Relaciones con las Cortes y Memoria Democrática del Gobierno de España. 


\begin{abstract}
Laburpena. Gerra Zibileko eta frankismoko Andaluziako memoria-lekuen kudeaketa publikoarekin lotutako jardueretara hurbildu nahi du artikuluak. Lehenik eta behin, Espainian biktima gehien izan zituen lurraldean frankismoak ezarritako errepresioa errepasatzen da labur eta zehatz; izan ere, errealitate haren ondorioz, inguru hartan badira zenbait leku biktimen memoriarekin lotuak daudenak. Gero, Andaluziako memoria-lekuei dagokien araudi espezifikoa aztertzen da. Araudi horretan oinarrituta, berrogeita hamalau memoria-leku izendatu ditu ofizialki Andaluziako Juntak, eta erreferentzia izan da beste lurralde batzuentzat ere. Aurrerago, memoria-lekuen garrantzia, heterogeneotasuna eta adibide esanguratsuak ere ematen dira aditzera. Artikuluaren idazleek eskarmentu luzea dute halako lekuak kudeatzen eta arautzen, orain existitzen ez den Andaluziako Juntako Memoria Demokratikoaren Zuzendaritza Nagusiko kide izandakoak baitira.
\end{abstract}

Gako hitzak. Lekuak; memoria; biktimak; errepresioa; Andaluzia.

\begin{abstract}
The text tries to approach the actions related to the public management of the places of memory of the Civil War and Francoism in Andalusia. In the first place, we review the repressive reality that Francoism implemented in the region with the highest number of victims in Spain and that gave rise to a series of spaces related to the memory of the victims. For this, we examine the specific regulations that have regulated them in Andalusia and that have been a benchmark for other regions, and the basis on which more than fifty places of memory have been officially declared by the Andalusian Government. The importance of these places, their heterogeneity and significant examples are also the subject of this article made from the experience in the elaboration of the norms and management of these spaces by their authors in the defunct General Management of Democratic Memory of the Government of Andalusia.
\end{abstract}

Keywords. Sites; Memory; victims; repression; Andalusia.

\section{Introducción}

En los últimos años los estudios llevados a cabo en España con objeto de profundizar en las distintas vertientes de la represión franquista se han multiplicado. $\mathrm{Al}$ interés de la universidad en general y de investigadores independientes se han sumado numerosas administraciones públicas, cuya intención ha sido el conocimiento más exhaustivo de la etapa de la Guerra Civil y del Franquismo para conseguir, entre otros objetivos, una efectiva aplicación de políticas públicas de memoria dirigidas especialmente a la reparación de las víctimas. A este impulso ha venido a sumarse en los últimos meses el Gobierno de España con la creación de una Secretaría de Estado de Memoria Democrática ${ }^{1}$.

1 Real Decreto 373/2020, de 18 de febrero, por el que se desarrolla la estructura orgánica básica del Ministerio de la Presidencia, Relaciones con las Cortes y Memoria Democrática. BOE núm. 43, de 19 de febrero de 2020 . 
Probablemente la eliminación de partidas presupuestarias y de la estructura relacionada con memoria historia por parte de los gobiernos del Partido Popular llevó a la práctica suspensión de la Ley 52/2007, de 26 de diciembre, por la que se reconocen y se amplían derechos y se establecen medidas a favor de quien sufrió persecución o violencia durante la Guerra Civil y la dictadura, conocida como Ley de Memoria Histórica ${ }^{2}$. Esta paralización a nivel estatal parece que espoleó a muchos gobiernos autonómicos a implementar iniciativas memorialistas para hacer frente a una demanda social cada vez más creciente y estimulada por la Ley de Memoria Histórica. Así pues, las comunidades autónomas de Navarra, Andalucía, Islas Baleares, Comunidad Valenciana, Aragón, Canarias, Extremadura o Asturias han ido aprobando en estos últimos años leyes específicas que venían a cubrir la inacción estatal ${ }^{3}$.

Relacionado con ese impulso de las políticas públicas de memoria a nivel regional, se ha desarrollado una normativa específica fundamentada en la idea de que era necesario implementar iniciativas políticas encaminadas a la dignificación y señalización de espacios históricos emblemáticos vinculados a la Guerra Civil y la represión franquista. Para ello se partió de un concepto de luǵares que abordaba espacios físicos concretos frente al trazado por Pierre Nora en su obra Les lieux de mémoire, donde se plantea una idea mucho más amplia, centrada en la identidad de la comunidad y cubriendo no solo los aspectos físicos, sino también otras expresiones culturales intangibles (banderas, canciones, leyendas... $)^{4}$.

Por tanto, todas las actuaciones desarrolladas en Andalucía desde un punto de vista normativo y administrativo sobre esta cuestión han ido dirigidas esencialmente a la dignificación, conmemoración y solemnización de los conocidos como lugares de memoria. Dentro de estas iniciativas el caso andaluz es, a nuestro entender, particularmente siǵnificativo debido a su carácter referencial para otras iniciativas normativas similares posteriores de otros territorios.

El análisis de la aplicación de esta normativa en Andalucía, así como el origen, la significación y la heterogeneidad de los lugares declarados en base a la normativa que se ha ido aprobando en los últimos años son, entre otras cosas, objeto de este artículo.

2 Junquera, 2013, https://elpais.com/politica/2013/10/05/actualidad/1380997260_542677.html [consultado el 06/08/2020].

3 Ver el esquema comparativo de la leǵislación sobre memoria histórica en el estado español, clasificados en los siguientes bloques, realizado por la Asociación de Memoria Social y Democrática (AMESDE). Ver García Bravo, 2018, https://www.cronicapopular.es/2018/12/un-decenio-de-legislacion-sobre-memoria-historica-en-espana/ [consultado el 06/08/2020].

4 Nora, 1984. 


\section{Los cimientos de los lugares de memoria en Andalucía}

La magnnitud de las consecuencias de la Guerra Civil y de la represión franquista se ha comenzado a definir de una manera más nítida desde el año 2000 aproximadamente en Andalucía. Tal es así que en los últimos tiempos se está completando un mapa general, aún por afinar debido a las dificultades en la investigación, de lo que desde un punto de vista cuantitativo supuso la represión en la región. Según los últimos estudios, contó con 57413 personas asesinadas por los golpistas, frente a las 8715 víctimas que causó la violencia en zona republicana $^{5}, 708$ fosas según el mapa oficial de fosas de la Guerra Civil y la represión franquista en Andalucía ${ }^{6}$ y más de 45000 exiliados $^{7}$. En este sentido, además de la represión física que se implementó a través de los consejos de guerra, los trabajos forzados, la creación del Tribunal Especial para la Represión de la Masonería y el Comunismo $^{8}$, etc., hay que tener en cuenta la vertiente económica de la represión franquista llevada a cabo durante la guerra y la posǵuerra en Andalucía a través de las Comisiones Provinciales de incautaciones de Bienes en las provincias ocupadas por las tropas rebeldes a la República y las actuaciones de los Tribunales de Responsabilidades Políticas entre 1939 y 1945 con base a la Ley de 9 de febrero de 1939 de Responsabilidades Políticas ${ }^{9}$, que para el caso andaluz se han podido analizar más de 60000 expedientes por parte de un equipo universitario donde participaron investigadores de ocho universidades públicas andaluzas ${ }^{10}$.

Estos datos reflejan la magnitud de la violencia ejercida durante tantos años sobre muchos andaluces, cuyas historias personales conocemos gracias a la memoria de los supervivientes y de los familiares de las víctimas, algunos de los cuales terminaron a finales del pasado siǵlo organizándose en asociaciones que han sido motor reivindicativo de esas memorias particulares convertidas, gracias en parte a su lucha, en una memoria colectiva.

Como consecuencia de esa demanda de la sociedad civil, de los estudios e investigaciones rigurosas y también de la sensibilidad del Parlamento andaluz y

5 Fernández Albéndiz y Giráldez Díaz, 2013, p. 52. Por otro lado, de las casi 58000 víctimas de la represión física, entre el 12 y el 14\% lo fueron después de abril de 1939, lo que demuestra que la mayoría de los asesinatos se llevaron a cabo auspiciados por los bandos de guerra, sin incoación de procedimiento, de forma especialmente ilegal. Ver Giráldez Díaz, 2014, p. 5.

6 Ver web de la Consejería de Cultura y Patrimonio Histórico de la Junta de Andalucía: https:// www.juntadeandalucia.es/orǵanismos/culturaypatrimoniohistorico/areas/memoria-democratica/ fosas/mapas-fosas.html [consultado el 06/08/2020].

7 Martínez López (coord.), 2014, p. 14.

8 Ley de 1 de marzo de 1940 sobre represión de la masonería y del comunismo, BOE núm. 62 de 2 de marzo de 1940, pp. 1537-1539.

9 BOE núm. 44 de 13 de febrero de 1939.

${ }^{10}$ Gómez Oliver, Martínez López y Barragán Moriana (coords.), 2015. 
del propio gobierno autonómico, a principios de los años dos mil se comenzaron a desarrollar políticas públicas de memoria que permitieron que Andalucía se convirtiera en una de las puntas de lanza de la memoria histórica en España ${ }^{11}$. Indemnizaciones a expresos y represaliados del Franquismo, Mapa de Fosas de Andalucía, creación de Comisariado de la Memoria Histórica, decreto de indemnizaciones a mujeres vejadas en su honor, convocatoria pública de subvenciones para proyectos memoriales dirigida a ayuntamientos, universidades y asociaciones, exhumaciones de fosas comunes, etc., son algunas de las iniciativas desarrolladas por el gobierno andaluz en esos años. Además, muchas de estas acciones se han llevado a cabo siguiendo un principio de colaboración entre universidades públicas, equipos de investigación, ayuntamientos y/o asociaciones memorialistas.

Es en ese contexto, en torno al año 2010, en el que se plantea por primera vez la necesidad de establecer una regulación en torno a los espacios físicos (fosas, cárceles, sitios de fusilamiento, etc.) relacionados con la Guerra Civil y la dictadura franquista. Y se plantea desde la idea de que si no se hacía pronto algo en este sentido, si no se trabajaba en la preservación, los espacios físicos relacionados con la Guerra Civil y la represión franquista seguirían desapareciendo y difícilmente se podrían abordar nuevos enfoques. Además, desde un punto de vista, si se nos permite, más emotivo, los lugares guardaban, en cierta forma, las historias de las víctimas que tuvieron relación con ellos, se trataba de una memoria física que podíamos tocar, traían al presente un pasado traumático que era necesario no olvidar. De esta forma, y una vez reconocidos en base a la normativa, estos espacios se podrían transformar en una nueva realidad que se proyectaría hacia el futuro. Para conseguir ese objetivo había que diseñar una herramienta jurídica que, además de abundar en la preservación y protección como decíamos anteriormente, pudiera complementarse con un instrumento censal que contuviera información necesaria y valiosa, con objeto de incitar a otras administraciones públicas a inventariar y promover esos sitios y lugares de memoria. Se trataba del Decreto 264/2011, de 2 de agosto, por el que se crean y regulan la figura de Lugar de Memoria Histórica de Andalucía y el Catálogo de Lugares de Memoria Histórica de Andalucía ${ }^{12}$.

${ }^{11}$ La primera iniciativa pública llevada a cabo por un Gobierno andaluz en relación con la implementación de iniciativas públicas de Memoria Histórica se desarrolló en el año 2001 mediante la publicación del Decreto 1/2001, de 9 de enero, por el que se establecen indemnizaciones a expresos y represaliados políticos que sufrieron privación de libertad por más de tres años y se acuerda abrir convocatoria pública para aquellos otros que sufrieron privación de libertad por menos de tres años, ambos como consecuencia de los supuestos previstos en la Ley 46/1977, de 15 de octubre, de Amnistía, BOJA núm. 11 de 27 de enero de 2001.

12 BOJA núm. 158 de 12 de agoosto de 2011. 
En esta norma los Lugares de Memoria Histórica de Andalucía quedarían definidos como «aquellos vinculados a hechos o acontecimientos singulares» ocurridos durante la Guerra Civil y la dictadura franquista, desde el 18 de julio de 1936, fecha de la sublevación militar contra el Gobierno legítimo de la II República Española, hasta el 29 de diciembre de 1978, fecha de entrada en vigor de la Constitución Española.

Tras esa primera cuestión clave como fue la definición, en la elaboración de la norma se afrontó otra cuestión compleja como era el proceso de declaración de los lugares de memoria de Andalucía, poniendo énfasis en dos aspectos que se pueden considerar como los pilares de la tramitación. Por un lado, la elaboración de un informe completo sobre su ubicación, toda la información histórica sobre los hechos y acontecimientos ocurridos en el mismo, todos los datos sobre las personas e instituciones que se vieron involucradas, así como cualquier otra información sobre el devenir histórico del lugarar o de las personas e instituciones asociadas al mismo. Y, por otro, las medidas a adoptar por las administraciones públicas para preservar los lugares de su desaparición o, en su caso, para procurar el mantenimiento de una huella o registro permanente que sirviera de recordatorio y homenaje por los hechos ocurridos en el Lugar, y donde fuera factible una señalización adecuada para su identificación permanente.

Ya aparecía como aspecto más relevante del procedimiento de declaración, que podía comenzar por iniciativa propia o a petición de personas o entidades interesadas, la preceptiva emisión de informe del grupo de trabajo designado por la Comisión Interdepartamental para el reconocimiento de las víctimas de la Guerra Civil y del Franquismo en la Comunidad Autónoma de Andalucía ${ }^{13}$, expresando su parecer favorable o contrario a dicha declaración, con las motivaciones históricas y científicas que resultaran procedentes. Nos parece importante destacar que solo cabía proponer la declaración de Lugar de Memoria Histórica cuando el informe del grupo de trabajo fuera favorable, dotándola así de la necesaria objetividad y estrechando el margen de discrecionalidad que pudiera existir, mediante el papel esencial que se otorgaba al informe motivado y vinculante del grupo de trabajo, integrado por personas expertas designadas a propuesta de la Junta de Andalucía, la Federación Andaluza de Municipios y Provincias y el Consejo Andaluz de Universidades.

Una vez aprobada la declaración por el Consejo de Gobierno y publicada en el Boletín Oficial de la Junta de Andalucía, los Lugares eran inscritos en el Catálogo de Lugares de Memoria Histórica de Andalucía, creado como instrumento para el conocimiento, la consulta y la divulgación de los mismos. De carácter público, sus datos podían ser consultados por la ciudadanía a través

${ }^{13}$ Creada por Decreto 521/2004, de 9 de noviembre, BOJA núm. 221 de 12 de noviembre de 2004. 
de Internet, accediendo a la página web de la consejería competente en materia de memoria histórica, conteniendo tanto la relación pormenorizada de los Lugáares declarados como la documentación asociada a cada uno de ellos.

Por último, en cuanto a las obligaciones de las personas titulares de bienes declarados, se establecía que si estas fueran administraciones públicas vendrían obligadas a garantizar la perdurabilidad, la identificación y la señalización adecuada de los mismos. Y en los casos en que su titularidad fuera privada, se procuraría alcanzar esos objetivos mediante acuerdos entre la consejería competente y las personas o entidades titulares.

Este fue el marco jurídico en el que el Gobierno andaluz declaró cincuenta Luǵares de Memoria Histórica en Andalucía ${ }^{14}$, como estandarte de otra forma de reparación, al situar en un mapa físico los espacios emblemáticos vinculados a medio siǵlo de la historia de Andalucía, pero sobre todo al hacerlo también con los protagonistas que con su sufrimiento, su sacrificio y su resistencia los erigieron como coordenadas para el recuerdo y contra el olvido. Lugares físicos, pero recubiertos de la piel y el sentimiento de aquellos que en ellos dejaron parte de una impronta de esperanza y desconsuelo, y sobre los que familiares, colectivos y administraciones de distinto ámbito han venido colaborando para situarlos, no como un ejemplo de desánimo, sino como un claro mensaje de la importancia del conocimiento, para la asimilación de la trascendencia objetiva de unos hechos, quizás para la traslación de unos a nuestro tiempo, para la no repetición de otros; y, en todo caso, para el recuerdo de ambos.

\section{Andalucía: coordenadas para la memoria histórica}

Aquello que puede verse nos genera preguntas; lo que no se ve y no se conoce, siquiera a partir de una realidad transferida, se convierte en desconocido y con ello, al multiplicarse, en sinónimo del peor enemigo de la memoria colectiva: el olvido y la injusticia que conlleva ${ }^{15}$. Probablemente algo parecido debieron pensar los responsables del desarrollo de las políticas públicas de memoria en Andalucía hace ahora una década; probablemente lo hicieran también conscientes de la esencia del Estatuto de Autonomía para Andalucía en el sentido de la necesidad de proteger el conocimiento y difusión de la historia de la comunidad andaluza. Y seguramente por todo lo dicho los dos primeros sitios vinculados al fenómeno memorialista en ser declarados lugares de memoria histórica de

\footnotetext{
${ }^{14}$ Ver https://www.juntadeandalucia.es/organismos/culturaypatrimoniohistorico/servicios/mapa/lugares-memoria-historica.html [consultado el 06/08/2020].

15 Mate, 2008, pp. 168-169.
} 
Andalucía fueron la casa de la que Blas Infante, conocido padre de la patria andaluza por sus anhelos de conseguir la mejora de las condiciones de vida de hombres y mujeres dentro de una Andalucía libre y solidaria, fue sacado para ser asesinado, y el lugar exacto de su fusilamiento.

Una casa y un punto kilométrico, un elemento perdurable en el tiempo y otro susceptible de ser modificado o sepultado, pero con el reto de preservar un simbolismo rememorador ${ }^{16}$. Quizás dos realidades muy distintas de lugar de la memoria pero unidas en torno a la necesidad de mantener un relato que hiciera honor a una tierra y sus gentes por el mero hecho de no dejar en el olvido su historia, y con ello garantizar esa sensación balsámica de pertenencia a un territorio, esa correa de transmisión con un pasado e identidad colectivos ${ }^{17}$. Serían la casa de Blas Infante y su lugar de asesinato donde, como dice Pierre Nora, se cristaliza y se refugia la memoria ligada a un momento particular, en nuestro caso, de la historia de Andalucía ${ }^{18}$.

Y es que, efectivamente, no se trataba sólo de preservar o proteger físicamente un espacio -de hecho, la declaración de un espacio como Lugar de Memoria Histórica de Andalucía se producía en algunos casos después de una «destrucción a mejor» de su estado original, como por ejemplo con no pocas fosas comunes-, sino también de garantizar un recuerdo, una historia, cierta reparación, y en todo caso una oportunidad para el debate y la reflexión, tanto en el presente como de cara al futuro ${ }^{19}$. La llamada «Casa de la Alegría», residencia de Blas Infante desde 1932 en que se hiciera cargo de la Notaría del municipio sevillano de Coria del Río y hasta el 2 de agosto de 1936 cuando fue detenido, y el kilómetro 4 de la carretera de Carmona donde fue fusilado de madrugada nueve días después, junto a otros destacados políticos sevillanos como José González y Fernández de la Bandera, exalcalde de Sevilla, el diputado y presidente de la Federación Provincial del PSOE Manuel Barrios Jiménez y Emilio Barbero Núñez, teniente de alcalde del Ayuntamiento de Sevilla ${ }^{20}$, fueron los dos primeros espacios declarados como Lugar de Memoria Histórica de Andalucía, el 30 de diciembre de 2011.

${ }^{16}$ López Fernández, 2014, p. 16.

17 Giráldez Díaz y Melero Varǵas, 2017.

${ }^{18}$ Nora, «Entre Memoria e Historia: la problemática de los lugares», http://www.comisionporlamemoria.org/archivos/jovenesymemoria/bibliografia_web/historia/Pierre.pdf [consultado el 06/08/2020].

${ }^{19}$ En relación con el tratamiento de los lugares de memoria como espacios para el debate y la reflexión se ha pronunciado la UNESCO en varias ocasiones. Ver https:/whc.unesco.orǵ/en/activities/933/ [consultado el 06/08/2020].

${ }^{20}$ Como afirma el historiador Juan Ortiz Villalba con el asesinato de todos estos conocidos políticos sevillanos «conmemoraban los sublevados la intentona de Sanjurjo del 10 de agosto de 1932 y se vengaban de su estrepitoso fracaso». Ver Ortiz Villalba, 2006, p. 258. 
No había llegado a aprobarse aún la orden que regularía su señalización ${ }^{21}$, pero se sentaban las bases para la revitalización de una memoria histórica sustentada en la preservación física de los espacios, así como en la oportunidad de inventariar, siquiera de forma simbólica, el escenario en el que murió una parte importante de una esencia social y política andaluza silenciada en su libertad, su reivindicación y su democracia por el ruido sordo de las balas; tal y como ocurriría muchos años después con Manuel Jesús García Caparrós, otro indiscutible icono de la lucha para la consecución de la autonomía andaluza, y cuyo espacio en el que fue abatido mortalmente en Málaǵa marcaría con sangre unas nuevas coordenadas para la memoria ${ }^{22}$.

El caso es que las primeras consecuencias efectivas de la regulación reglamentaria de 2011 sobre lugares de memoria tenían que ir orientadas al afianzamiento de una identidad andaluza que, como otras muchas cosas, había quedado aletargada en sus aspiraciones de autonomía política con el terror caliente del verano de 1936. Desde el nacimiento oficioso del sentimiento de regionalismo andaluz en el tercer tercio del siǵlo XIX, sustentado en hitos como la Constitución de Antequera, y hasta muy pocos días antes de la sublevación previa a la Guerra Civil, se habían ido dando los pasos hacia una aspiración de autonomía que podía tener en la Constitución de 1931 su primera gran oportunidad legal ${ }^{23}$.

Después vendría la aprobación por parte de las diputaciones andaluzas de redactar un anteproyecto de Estatuto, en 1932, que cristalizaría un año más tarde, en el contexto de la Asamblea de Córdoba, en las Bases de un Estatuto de Autonomía que, cuando parecía afrontar un ritmo decidido y definitivo, tropezó primero con la victoria del radical-cedista en las elecciones de noviembre de 1933 -que frenó cualquier intención autonomista- y con el escaso marǵen de maniobra tras la victoria de un Frente Popular absorbido por los conflictos diarios de tipo laboral y social, y por atenuar una constante amenaza de sublevación que había nacido con la propia República, en abril de 1931, y que ahora tomaba, con nuevos bríos desde febrero de 1936, un camino de no retorno que tendría su primera parada en julio de ese mismo año. La sublevación y posterior Guerra Civil -con la eliminación física de Blas Infante y el adormecimiento de

${ }^{21}$ Orden de 27 de febrero de 2012, por la que se regula la señalización de los Lugares de Memoria Histórica de Andalucía, BOJA núm. 52 de 15 de marzo de 2012.

22 Burgos, 2017.

${ }^{23}$ Cruz Artacho, 2013. El propio Blas Infante veía el cambio de régímen, en 1931, como una oportunidad de «trabajar por la consolidación de la República, seguir laborando por la reconstrucción histórica de Andalucía y preparar en estas interesantísimas circunstancias interregionales, la intervención de nuestro pueblo como término federativo en la construcción del nuevo ser de España». El Liberal, 21 de abril de 1931. 
su herencia intelectual e ideológica- laminarían por décadas el anhelo autonomista de Andalucía, pero proporcionarían al mismo tiempo el nacimiento de un incontestable vínculo entre sentimiento andaluz y memoria histórica -nacionalidad histórica- que alumbraría por fin el Estatuto de 1981.

Sea como fuere, las declaraciones de la Casa de la Alegría de Coria del Río y el Kilómetro 4 de la carretera de Carmona como primeros lugares de memoria histórica de Andalucía supusieron el inicio de un reconocimiento oficial que, amparado en el Decreto 264/2011, vendría a aplicarse en los años siguientes sobre un numeroso grupo de espacios emblemáticos que, de nuevo con su pervivencia física o con la concentración de su potente carga simbólica sobre un hito -es preciso señalar que se trata de una reglamentación que no aborda luǵares en abstracto, como otro mecanismo más de preservación del conocimiento y el recuerdo-, podían ayudarnos a conocer mejor, o como mínimo a no olvidar, la historia de un territorio, en su esperanza y en su convulsión.

Cincuenta lugares para un marco temporal de poco más de cuatro décadas; medio centenar de sitios y símbolos que, en su conjunto, iban a constituir la mejor expresión del reconocimiento institucional a la necesidad del recuerdo, como inapelable herramienta pedagógica, y como respuesta de nuevo a una demanda de una parte de la sociedad -familiares de víctimas, entidades memorialistas, grupos de investigación, ayuntamientos, diputaciones e incluso particulares, etc.- que seguía reclamando formas de reparación desde la solvencia historiográfica del soporte documental que en muchos casos ellos mismos aportaban.

Los lugares de la memoria de Andalucía transitarán por variados caminos, a menudo cruzados, y que en la gran mayoría de los casos no terminarán sino mostrando -y corroborando- la brutal y poliédrica violencia ejercida en las ocho provincias de Andalucía desde la sublevación de julio de 1936 y durante toda la dictadura franquista ${ }^{24}$. Así se dará por ejemplo, y además en su máxima expresión, en lugares en los que ni siquiera llegó a haber guerra o esta fue fugaz, como en Cádiz, donde el Castillo de San Sebastián y los Muros de Puerta Tierra serían escenarios del asesinato de muchos de aquellos que no dudaron en defender la legalidad republicana frente a la sublevación ${ }^{25}$; lo mismo que en la Plaza de la Constitución de Baena ${ }^{26}$, en los muros del parque Moret de Huelva ${ }^{27}$, o en las tapias del cementerio de Granada, adonde llegaban cada amanecer camiones

\footnotetext{
${ }^{24}$ Melero Varǵas, 2015.

25 Domínguez, 2004.

${ }^{26}$ Bedmar, 2009.

${ }^{27}$ Ver https://www.juntadeandalucia.es/organismos/culturaypatrimoniohistorico/areas/memoria-democratica/fosas/mapas-fosas.html [consultado el 06/08/2020].
} 
procedentes de una superpoblada cárcel granadina, repletos de presos que no portaban encima más que una tarjeta de identificación para ser volcada, tras su fusilamiento, en los libros de registro del Cementerio ${ }^{28}$. Caminos de muerte, como la icónica carretera entre Víznar y Alfacar, paisajes del terror, como el barranco del Carrizal de Órgiva, todos ellos en la provincia granadina, y ambos cementerios improvisados ${ }^{29}$.

Queda claro pues que algunos de ellos también servirían de enterramiento, participando por tanto de un doble inventario que los incluía como parte de otro proyecto pionero en España: el del Mapa de Fosas de Andalucía ${ }^{30}$, y donde se incluirían también todas las fosas comunes declaradas como lugar de memoria, en su gran mayoría en cementerios: Puerto Real en Cádiz, Baena, Córdoba y Santaella en la provincia cordobesa, Almonte, La Palma del Condado y Nerva en Huelva, Andújar, Linares, Martos y Úbeda en Jaén, Fuentes de Andalucía y Puebla de Cazalla en Sevilla, Antequera, Ronda y Teba en la provincia malagueña, y cuyo caso, este último, ya debía hacer vislumbrar la necesidad de ampliar el marco temporal de aplicación de la legislación memorialista, para dar por ejemplo cobijo a hitos ocurridos con anterioridad a la sublevación, como por ejemplo la inusitada dimensión que en este municipio llegaría a alcanzar la Revolución de octubre de 1934, y estableciendo su nexo con la represión sublevada a partir de 1936.

En otros casos el cementerio sería el pueblo en sí mismo, como en la pedanía onubense de Membrillo Bajo, donde todos sus habitantes fueron asesinados, las casas incendiadas y las tierras usurpadas para afines de la sublevación; o incluso en otros casos estos enterramientos ilegales quedarían fuera de todo espacio público, como en el caso del municipio malagueño de Istán, cuya fosa se asentaba entre castaños y almendros de una propiedad privada.

Se da la paradoja de que, concretamente en el caso de las fosas comunes, ha llegado en ocasiones antes la reparación parcial en forma de señalización oficial que la plena en forma de recuperación de los cuerpos y su entierro diǵno. Ello

28 Gil Bracero y Brenes, 2009.

${ }^{29}$ Baquero, 2013, https://www.eldiario.es/andalucia/barranco-Lorea_0_148735134.html [consultado el 06/08/2020].

${ }^{30}$ Un proyecto pionero en España y que, promovido desde la Junta de Andalucía, puso en colaboración a las nueve universidades públicas de la comunidad, presentando en 2009 una herramienta de trabajo muy útil para el conocimiento de la represión en su más trágica intensidad, con 614 fosas. En 2018, como resultado de la muy activa labor de localización y exhumación de fosas promovida desde la ya extinta Dirección General de Memoria Democrática de la Junta de Andalucía, se presentó una versión actualizada de esta herramienta interactiva, y que elevaba el número de enterramientos ileǵales vinculados a la Guerra Civil y la posǵuerra en el subsuelo andaluz a 708. Ver https:// www.juntadeandalucia.es/orǵanismos/culturaypatrimoniohistorico/areas/memoria-democratica/ fosas/mapas-fosas.html [consultado el 06/08/2020]. 
supone una inequívoca señal de los sinuosos caminos por los que el movimiento de memoria histórica ha venido transitando desde sus primeras manifestaciones, que siempre han girado en torno a la demanda de las familias por encontrar a sus deudos, y reivindicando mientras tanto la protección de esos sitios de memoria que evitara su destrucción y su olvido. Por decirlo de otra forma, un déficit de memoria que sólo en algunos momentos de estos últimos años ha conseguido aminorarse y que en la actualidad se ha consolidado en el aletarǵamiento y la inacción.

Este hecho, el de adelantar la señalización a la propia exhumación, ha generado incluso alguna situación, tan peculiar como frustrante, en el sentido de no haber sido capaces de corroborar con lo físico la transmisión oral de un hecho asumido por el grupo como una certeza. Así ocurriría con la conocida Fosa de El Aguaucho, en el municipio sevillano de La Campana, icono junto con otro luǵar de memoria de Andalucía como la Fosa de las Mujeres en Grazalema (Cádiz) de la represión ejercida por cuestiones de género, y donde el resultado de una ingente intervención arqueológica reclamada por familiares de las desaparecidas -16 jóvenes de la vecina localidad de Fuentes de Andalucía, violadas, vejadas y asesinadas por falangistas-, así como por el movimiento memorialista no haría sino confirmar que se había cumplido con creces uno de los objetivos de los represores con sus víctimas, la ocultación del delito, pero nunca otro quizás tan importante como el primero, y contra el que precisamente se combate desde los lugares de memoria: hacer desaparecer todo rastro de recuerdo, de existencia ${ }^{31}$. Un recuerdo en algunos casos de tanta potencia que ha llegado a minimizar que algunos de estos sitios no nacieron ex profeso para el horror, sino que forman parte de ese otro inventario de lugares que, como las vidas de cientos de miles de personas, tuvieron que adaptarse a los estragos de una coyuntura represiva que lo copaba todo.

La Antigua Cárcel del Ingenio de Almería ${ }^{32}$, el Cortijo de El Marrufo de Jerez de la Frontera -en el extremo oriental del valle de La Sauceda ${ }^{33}$, también lugar de memoria mítico por la potente resistencia ejercida frente al imparable avance de las tropas sublevadas- o la Antigua Comisaría de Investigación y Viǵilancia de la calle Jesús del Gran Poder de Sevilla ${ }^{34}$, que nacieron para generar riqueza, educar las mentes y remover conciencias, se convertirían en improvisados centros de señalamiento, reclusión, tortura y muerte.

\footnotetext{
${ }^{31}$ Serrano, 2017, p. 124.

32 Rodríguez Padilla, 2007.

${ }_{33}$ Ver http://www.casamemorialasauceda.es/index.php/es/esposicion/sauceda/177-bombardeo-saqueoy-muerte [consultado el 06/08/2020].

34 García Márquez, 2014, pp. 145-149.
} 
Efectivamente la Guerra Civil y la posterior dictadura alteraron el paisaje andaluz en su conjunto, en los pueblos y ciudades y en sus entornos naturales, como forma de resiliencia ante una nueva cotidianeidad en la que podían incluirse la defensa de un territorio en pleno fragor de la batalla, las necesidades para un nuevo desarrollo agrícola o, de nuevo, la represión o la mera supervivencia física. La batalla de Lopera en Jaén, la de Valsequillo en Córdoba, o toda la línea que comprendía el conocido como cerco de Granada, se convirtieron en lugares de memoria dentro del espacio natural por fundados motivos que iban más allá de la constatación de la ya sobradamente conocida profunda asimetría a la hora de afrontar el combate entre los dos bandos, en materiales, números y disciplina, sino que aportaron un riquísimo patrimonio arqueológico bélico de nidos de ametralladoras, trincheras, búnkeres y otras estructuras defensivas $^{35}$. Iǵualmente rica sería la aportación de una arquitectura subterránea fundamental para entender cuestiones que enǵlobaban el pavor ante una masacre constante en forma de bombardeos aéreos o la colaboración ciudadana para la supervivencia, como los refugios antiaéreos de Jaén o Almería.

Y desde luego la huella indeleble dejada por la importancia de una obra de inǵeniería hidráulica como fue el canal del Bajo Guadalquivir; un proyecto contemplado desde el siǵlo XIX, fundamental para la conversión de miles de hectáreas en tierras aprovechables de regadío, y que concluyó con un mastodóntico canal de riego de 82 kilómetros de longitud a través de siete términos municipales de la provincia de Sevilla; pero también con la mano de obra de entre 6000 y 7000 penados que convirtieron a este «Canal de los Presos» en el máximo exponente del trabajo en condiciones de esclavitud de los prisioneros republicanos para beneficio del régimen franquista ${ }^{36}$. Unas condiciones de vida muy similares a las que sufrirían los más de 3000 prisioneros que llegaron a copar el campo de concentración habilitado en isla Saltés, en Huelva, en otro ejemplo de la adaptación de un paraje natural en espacio de represión; hambre, hacinamiento, insalubridad y enfermedades que se unirían al miedo y la tortura, desde el final de la guerra hasta las postrimerías mismas de la dictadura, en prisiones como la de Puerto de Santa María en Cádiz, las antiguas prisiones provinciales de Granada y Huelva -esta última además como máximo exponente del castigo sobre la población homosexual y trans- la Antigua Prisión y la Cárcel de Mujeres de Málaǵa o la Cárcel de Ranilla de Sevilla ${ }^{37}$.

35 Pantoja Vallejo, 2006

${ }^{36}$ «El Canal de los Presos». Revista Recuperando la Memoria de la Historia social de Andalucía. CGT Andalucía, año 2001. Véase también: http://www.todoslosnombres.orǵ/content/materiales/ guia-didactica-el-derecho-conocer-09-el-trabajo-forzado-en-el-Franquismo-el-canal [consultado el 06/08/2020].

37 Fernández Luceño, 2018. 
Muerte y cautiverio para los apresados procedentes de los frentes o que habían permanecido confiados en la retaguardia; muerte y persecución para aquellos que decidieron huir con el miedo como único delito cometido. Andalucía también ostenta el triste honor de contar entre sus lugares de la memoria el que recuerda, en la salida de Málaǵa en las estribaciones del río Guadalfeo sobre el Mediterráneo por el municipio granadino de Salobreña: la carretera de Málaga a Almería, el mayor éxodo de población civil en Europa hasta la guerra de los Balcanes, y en la que llegarían a coincidir, según los últimos estudios, en torno a 300000 personas procedentes de toda Andalucía, desde las que volcaron desde el interior hacia la costa, como las que siguieron desde Cádiz toda la franja litoral occidental ${ }^{38}$. Muchos de ellos morirían en el propio trayecto, otros serían interceptados por tropas italianas y sublevadas españolas y deportados a sus poblaciones de origen, donde tendrían que rendir cuentas. Los menos conseguirían llegar a Almería, donde también se producirían no pocas bajas como consecuencia de los incesantes bombardeos a los que sería sometida la capital almeriense.

Los hubo que consiguieron continuar hacia el norte por la zona de Levante, y los que incluso cruzaron la frontera al extranjero, fundamentalmente tras la ocupación de Cataluña, desembocando en campos de refugiados en Francia, y de ahí siendo deportados al campo de concentración austriaco de MauthausenGusen -sobre el que celebramos el día del 75 aniversario de su liberación en el momento en el que estamos escribiendo estas líneas-. Más de 1100 andaluces terminarían en campos de exterminio nazi, de los que la gran mayoría de asesinados procedían precisamente de Almería. Un bosque de columnas alegórico, símbolo de la lucha y el sufrimiento, los recuerda en el parque de las Almadrabillas de la ciudad ${ }^{39}$.

Por último, otros no se quedaron en sus pueblos cuando estos fueron ocupados, ni huyeron, ni cruzaron la frontera. Antiguos combatientes en las filas del Ejército Popular de la República en su mayoría, decidieron continuar su lucha integrando la resistencia guerrillera antifranquista en Andalucía ${ }^{40}$, y hasta bien entrada la década de los cincuenta del siglo pasado. La ruta guerrillera de Los Jubiles, en Montoro, o la del barranco de La Huesa, en Villaviciosa, ambas en Córdoba, representan como espacios de memoria dos de los principales exponentes de la lucha activa frente al Franquismo mucho más allá del final de una Guerra Civil que lo cambió todo, pero que otorga toda la razón de ser a estas líneas.

\footnotetext{
${ }^{38}$ Fernández Martín, 2016.

${ }^{39}$ Checa, Río y Martín, 2006.

${ }^{40}$ Melero Varǵas, 2014.
} 
En sólo dos años, diciembre de 2011 y el mismo mes de 2013, fueron declarados como lugares de memoria histórica de Andalucía cincuenta espacios vinculados a la sublevación, la Guerra Civil y el Franquismo en nuestra región, y con ello a toda la paleta cromática de actitudes ciudadanas que contribuyeron a construir un mapa andaluz repleto de coordenadas físicas y simbólicas, que no constituyen sino un muestrario de otros muchos escenarios esenciales para poder entender mejor una parte esencial de la historia de Andalucía, en su heroicidad y en su miseria, pues ambas eran esencias que viajaron juntas, como si de una columna mixta de mineros, guardia civiles y carabineros se dejara caer sobre La Pañoleta de Camas, una calurosa tarde de julio de $1936^{41}$.

Casi cuatro años más tarde, un 18 de julio y tras el dictamen favorable de un grupo de expertos, se daba por concluida la fase de valoración sobre otros catorce espacios para su inclusión en el Inventario de Lugares de Memoria Democrática de Andalucía, de los que la mayoría aún permanecen en una incierta fase de tramitación administrativa que, a buen seguro, tiene mucho que ver con el cambio de gobierno en Andalucía, de lo que da muestra el hecho de que hubiera que esperar hasta el 30 de junio de 2020 para que el Consejo de Gobierno aprobase incluir en el Inventario de Lugares de Memoria Democrática de Andalucía la Jefatura Superior de Policía de La Gavidia y el lugar donde fue herido mortalmente Francisco Rodríguez Ledesma (ambos en Sevilla) y el refuǵio antiaéreo de la Plaza de España en Villanueva de Córdoba (Córdoba). Inactividad que hace que, dos años después de dar luz verde a la tramitación de estos expedientes, el entorno memorialista se encuentre expectante ante tal demora en la declaración como lugares de memoria democrática de Andalucía de la fortificación del estrecho de Gibraltar (Cádiz), la Colonia de Víznar (Granada), el Convento de Santa Úrsula, el Campo de concentración de Santiago e Higuera de Calatrava y la Cárcel Vieja de Úbeda (Jaén), el Palacio de la Aduana (Málaǵa) o la Sede de la Capitanía General de La Gavidia en Sevilla.

Consecuencia asimismo de la ralentización en los resultados que debieran proporcionarse desde los instrumentos y herramientas públicas y legales de reparación de la memoria, otras 36 solicitudes de declaración sobre las que se solicitó el preceptivo dictamen al Grupo de Trabajo sobre Lugares y Senderos de Memoria Democrática de Andalucía, creado en el seno del Consejo de la Memoria Histórica y Democrática de Andalucía, duermen el sueño de los justos desde octubre de 2018. Son reclamaciones que perviven y se nutren de aquellos colectivos memorialistas, asociaciones de vecinos o particulares que han sido promotores de su declaración,

${ }^{41}$ Sobre los sucesos de la Pañoleta en el municipio sevillano de Camas son numerosos los testimonios y publicaciones en prensa. Como ejemplo, ver https://www.diariodehuelva.es/2019/06/28/dos-investigadores-ponen-nombre-a-todos-los-fusilados-en-la-panoleta/ [consultado el 06/08/2020]. 
y que continúan reclamando un señalamiento justo que evite algo que su desaparición física pueda acarrear, su olvido en la vorágine de la Historia, su nimiedad para el conocimiento colectivo del futuro. Así ocurriría por ejemplo con Villa Maya, en Málaǵa, residencia del cónsul de México en España en 1936, Porfirio Smerdou, el llamado «Schindler de la Guerra Civil» por haber logrado salvar a más de 600 personas de ambos bandos al darles refugio en esta vivienda ${ }^{42}$. En 2019, ante la indolencia de la administración local malaǵueña y como consecuencia directa de la paralización de las políticas públicas de Memoria en Andalucía, una excavadora logró lo que no habían sido capaces las bombas, ni sublevadas ni republicanas 80 años antes: hacer sucumbir a un espacio en el que una parte de España, sin importar la que fuera en ese determinado momento, encontró su abrigo frente a esa otra que, como rezaba el poema de Antonio Machado, habría de helar el corazón de sus hijos ${ }^{43}$.

\section{Reforzamiento normativo de los Lugares de Memoria Democrática}

El 15 de marzo de 2017, en una sesión plenaria con la tribuna de invitados repleta de víctimas y familiares y miembros de asociaciones andaluzas, el Parlamento de Andalucía aprobaba la Ley 2/2017, de 28 de marzo, de Memoria Histórica y Democrática de Andalucía ${ }^{44}$, sin ningún voto en contra, tras un amplio debate y después de una larǵa tramitación parlamentaria iniciada en octubre de $2015^{45}$. Con carácter general la nueva ley tenía por objeto, sucintamente, la regulación de las políticas públicas para la recuperación de la memoria democrática de Andalucía, con la finalidad de garantizar el derecho de la ciudadanía andaluza a conocer la verdad de los hechos acaecidos, así como la protección, conservación y difusión de la memoria democrática como legado cultural de Andalucía, en el período que va desde la Segunda República, la Guerra Civil, la Dictadura franquista y la transición a la democracia hasta la entrada en vigor del primer Estatuto de Autonomía para Andalucía en 1981.

Lo que interesa destacar aquí es que el dedicar un Capítulo a regular exhaustivamente los «Lugares y senderos de memoria democrática»-siǵnificativamente

${ }^{42}$ Egea, 2019, https://cadenaser.com/emisora/2019/03/29/ser_malaga/1553868549_968050.html [consultado el 06/08/2020].

43 Machado, 2006.

${ }^{44}$ BOJA núm. 63 de 3 de abril de 2017.

${ }^{45}$ Rengel, 2017, https:/www.huffingtonpost.es/2017/03/16/andalucia-aprueba-la-pionera-ley-dememoria-democratica_a_21898391/[consultado el 06/08/2020]. 
inserto en su Título II sobre «Reparación a las víctimas»- supone un evidente blindaje legal y viene a marcar un antes y un después en la regulación de los mismos, tanto por su alcance integral como por la incorporación de contenidos novedosos en la materia, tales como un estricto régimen jurídico de protección, obligaciones para sus titulares o la incorporación de la figura de Sendero de Memoria Democrática de Andalucía. Además se afrontaban las dudas que hubiera podido suscitar la regulación reglamentaria que venía a sustituir, esto es, su delimitación conceptual, qué era (y qué no era) un lugar de memoria democrática. Con ello se abordaba la cuestión del posible riesgo de la declaración expansiva de lugares de memoria, optándose por una definición más precisa de Lugar de Memoria Democrática de Andalucía como:

aquel espacio, inmueble o paraje que se encuentre en Andalucía y revele interés para la Comunidad Autónoma como patrimonio histórico, sin perjuicio de lo dispuesto en la Ley 14/2007, de 26 de noviembre, del Patrimonio Histórico de Andalucía, por haberse desarrollado en él hechos de singular relevancia por su significación histórica, simbólica o por su repercusión en la memoria colectiva, vinculados con la lucha del pueblo andaluz por sus derechos y libertades democráticas, así como con la represión y violencia sobre la población como consecuencia de la resistencia al golpe de estado de 1936, la Dictadura franquista y por la lucha por la recuperación de los valores democráticos hasta la entrada en vigor del Estatuto de Autonomía de Andalucía el 11 de enero de 1982, y que haya sido inscrito por decisión del Consejo de Gobierno de la Junta de Andalucía en el Inventario de Lugares de Memoria Democrática de Andalucía que se regula en el artículo 23.

Como se puede observar, la consideración como lugar de memoria democrática de Andalucía, y la consiguiente aplicación del régimen protector, se vinculaba a la concurrencia, no solo de los elementos materiales que lo hicieron acreedor de tal declaración, sino a su efectiva inscripción en el Inventario. En cuanto a estos elementos materiales, la apuesta por una definición más precisa venía acompañada de una ampliación de su ámbito temporal que, si recordamos el anterior Decreto 264/2011, limitaba los Lugares de Memoria Histórica a aquellos vinculados a hechos o acontecimientos singulares ocurridos durante la guerra ocasionada por el golpe de estado militar y la dictadura franquista. Además, se reforzaba la coherencia con el objetivo general de la Comunidad Autónoma plasmado en el artículo 10.3.24 $4^{46}$ del Estatuto de Autonomía para Andalucía, así como con el objeto de la propia ley que hemos reseñado, al vincular estos

${ }^{46}$ Establece que los poderes públicos velarán por la salvaguarda, conocimiento y difusión de la historia de la lucha del pueblo andaluz por sus derechos y libertades. 
hechos de singular relevancia requeridos con la lucha del pueblo andaluz por sus derechos y libertades democráticas, así como con la represión y violencia como consecuencia del golpe de estado y la dictadura franquista por la lucha por la recuperación de los valores democráticos.

Una vez así definidos los lugares de memoria democrática, la disposición adicional primera de la nueva ley abría la puerta a que los lugares de memoria histórica de Andalucía declarados conforme a la normativa anterior tuvieran la consideración de lugares de memoria democrática y quedasen inscritos en el Inventario. Este proceso ya se puso en marcha mediante la Resolución de 15 de mayo de 2018, de la Dirección General de Memoria Democrática, por la que se sometió a información pública la inscripción de los cincuenta Lugares de Memoria Histórica declarados por Acuerdos del Consejo de Gobierno de fechas 30 de diciembre de 2011, 20 de marzo de 2012 y 27 de diciembre de 2013 en el Inventario de Lugares de Memoria Democrática de Andalucía ${ }^{47}$. Sin embargoo, aunque la consejera de Cultura y Patrimonio Histórico anunció en sede parlamentaria ${ }^{48}$ que, terminados los trámites de información pública y de audiencia pública, se estaba en disposición de finalizar la tramitación para su inclusión definitiva en el Inventario en agosto de 2020, no hay noticias sobre la resolución del procedimiento ni información sobre el limbo jurídico administrativo en que estos lugares se encuentran.

Como se ha adelantado, sin duda, uno de los elementos claves de la nueva regulación lo constituía la creación del Inventario de Lugares de Memoria Democrática de Andalucía, puesto que trascendía de un mero instrumento de conocimiento, consulta y divulgación de los mismos, siendo la inscripción en el mismo una pieza esencial para la consideración de un Lugar de Memoria Democrática como tal y para la aplicación del régimen de protección que la ley establecía.

Respecto del procedimiento para la inscripción en el Inventario, que podría ser instada por cualquier persona física o jurídica, mediante escrito razonado, cabe valorar positivamente que se recuperara la necesidad de informe de un comité de expertos respecto de las solicitudes que se formulasen. Así se hizo al establecer como una de las funciones del nuevo Consejo de Memoria ${ }^{49}$ la de emitir informe preceptivo sobre las solicitudes de incoación del procedimiento para la inscripción en el Inventario, en el que expresase su parecer favorable o contrario a la misma, con las motivaciones históricas y científicas que resultasen proceden-

47 BOJA núm. 98 de 23 de mayo de 2018.

${ }^{48}$ Diario de Sesiones del Parlamento de Andalucía núm. 45, de 27 de marzo de 2019, Comisión de Cultura y Patrimonio Histórico.

${ }^{49}$ Decreto 93/2018, de 22 de mayo, por el que se crea y regula el Consejo de la Memoria Histórica y Democrática de Andalucía, BOJA núm. 101 de 18 de mayo de 2018. 
tes en orden a acreditar la concurrencia de las circunstancias exigidas en la ley. A estos efectos, se constituyó en su seno un específico grupo de trabajo ${ }^{50}$.

Prueba del esencial papel que la ley daba a la inscripción en el inventario de los terrenos o inmuebles declarados como Lugares de Memoria Democrática, era el hecho de que la misma comportara el establecimiento de obligaciones concretas a las personas propietarias, titulares de derechos o simples poseedoras de los mismos, sin parangón en la normativa anterior. Como prueba también del fuerte compromiso con la preservación y pervivencia de estos lugares era el hecho de que la mera incoación llevara aparejada la anotación preventiva del bien en el Inventario, determinando la suspensión cautelar de las correspondientes licencias municipales de parcelación, edificación o demolición, así como de los efectos de las ya otorgadas, hasta tanto se obtuviera la autorización de la consejería competente en materia de memoria democrática.

Porque es así como la ley se sirve de instrumentos para garantizar la pervivencia de la memoria, estableciendo para las personas referidas, sean públicas o privadas, un deber de conservación y mantenimiento para la salvaguarda de sus valores; incorporando la obligación de permitir su visita pública cuatro días al mes, en días y horas previamente señalados; posibilitando la inspección, y facilitando la información sobre el estado del lugar y su utilización. Para ello, el legislador había optado por trasladar a la regulación de las obligaciones de los titulares de Lugares que nos ocupan las recogidas en la Ley 14/2007, de 26 de noviembre, del Patrimonio Histórico de Andalucía ${ }^{51}$, para las personas titulares de bienes integrantes del Patrimonio Histórico Andaluz ${ }^{52}$, lo que si bien podría plantear algunas dificultades en una materia por su propia naturaleza conflictiva, y por ende necesitada del mayor nivel de seguridad jurídica posible, no dejaba lugar a dudas sobre el firme compromiso con la protección de los lugares de memoria democrática en Andalucía.

En la misma línea y como otra gran novedad de la ley, se regula un exiǵente régimen de protección y conservación, optándose aquí también por trasladar medidas y acciones que estaban reguladas en la mencionada Ley del Patrimonio Histórico de Andalucía, por ejemplo, en lo que respecta a los requisitos del proyecto de conservación ${ }^{53}$ o los deberes de solicitud de autorización o comunicación, es-

${ }^{50}$ El Grupo de Trabajo sobre Lugares y Senderos de Memoria Democrática de Andalucía era presidido por el responsable de Memoria Democrática e inteǵrado por representantes de la Consejería competentes en Educación y Cultura, una catedrática de Historia Contemporánea de universidad, dos representantes de asociaciones memorialistas y de la Federación Andaluza de Municipios y Provincias.

${ }^{51}$ BOJA núm. 248 de 19 de diciembre de 2007.

52 Véase el artículo 14 de la Ley 14/2007, de 26 de noviembre, BOJA núm. 248 de 19 de diciembre de 2007.

${ }^{53}$ Contendrá un estudio histórico del Lugar, un diaǵnóstico de su estado de conservación actual, así como una propuesta de actuación y un presupuesto económico de ejecución (art. 28.5). 
tablecidos respectivamente en los apartados 3 y 5 del artículo 33, respecto de los bienes BIC y catalogados.

Por tanto, se atribuía a la consejería competente en materia de memoria democrática de herramientas potentes en la tarea de la preservación de la memoria. Por un lado, la potestad de impedir un derribo y suspender cualquier clase de obra o intervención en un Lugar inscrito en el Inventario, o con anotación preventiva en el mismo. De otro lado, la necesidad de autorización por la misma, con carácter previo a las restantes autorizaciones o licencias para cualquier cambio o modificación que se desease llevar a cabo, con la finalidad de salvaguardar los valores históricos, ambientales, paisajísticos, pedagógicos, etnográficos, antropológicos u otros singulares que hubieran motivado su inscripción en el Inventario. Complementariamente se contemplaban una serie de medidas de protección en relación con instrumentos de ordenación del territorio, urbanismo, prevención y control ambiental. Vistas sintéticamente las obligaciones incorporadas, la nueva ley contemplaba para los supuestos de falta de cumplimiento de las mismas tanto la vía expropiatoria como la imposición de medidas sancionadoras. El régimen sancionador tipificaba varias infracciones que se clasificaban en muy graves, graves y leves, que podrían sancionarse con sanciones pecuniarias y no pecuniarias.

Podemos afirmar sin riesgo a equivocarnos que esta ley supone, sin duda, un antes y un después en la regulación de los Lugares de Memoria Histórica y Democrática de Andalucía. Lo es por el alcance de la misma, porque incorpora elementos hasta entonces no regulados -obligaciones de los titulares, régimen de protección o sancionador- y porque ofrece un conjunto normativo completo de aplicación a esta realidad, sin perjuicio de que la ley reclame un desarrollo reglamentario, bien de manera expresa en algunos aspectos, como son la coordinación con el resto del Inventario de Bienes Reconocidos, la determinación de las obras o actuaciones no sometidas a autorización, y en lo relativo a la señalización, o bien los que sean necesarios para aclarar conceptos jurídicos indeterminados. Pero la Ley de Memoria Histórica y Democrática de Andalucía ha supuesto también un hito porque se ha convertido en una referencia para otras comunidades autónomas a la hora de regular esta materia como parte de sus leyes de reparación y no repetición.

\section{Conclusiones}

La realidad de la Guerra Civil y la represión en Andalucía está marcada por unos datos de víctimas, fosas, exiliados, etc., muy elevados en comparación con otras regiones españolas, lo que pone de manifiesto que afectó a miles de andaluces y andaluzas y que la demanda de reparación por parte de las víctimas ha 
estado siempre justificada. Así, además de esta reivindicación que se fue materializando desde finales de los años noventa, la demanda organizada y permanente de las víctimas a través de entidades memorialistas, junto con la sensibilidad que el gobierno tuvo con la memoria, desembocaron en la implementación de una política pública llevada a cabo por la administración autonómica y los ayuntamientos con la colaboración de colectivos memorialistas y familiares de las víctimas, con el apoyo entre 2007 y 2011 del Gobierno de España. Dentro de estas iniciativas el tratamiento que debía darse a los espacios memoriales siempre fue caballo de batalla de los familiares de las víctimas, sobre todo en lo concerniente a aplicar un nivel de protección que impidiera la desaparición de los mismos.

Esta demanda tuvo su debido eco en el impulso institucional materializado a través de normas específicas para el reconocimiento, declaración y preservación de los lugares de memoria, cauce imprescindible para la implementación de medidas de protección y divulgación. Un marco normativo que, desde su primera plasmación de carácter reglamentario, favoreció la declaración de cincuenta y cuatro lugares de memoria en Andalucía, caracterizados por su heterogeneidad, repercusión social en sus provincias y en la comunidad autónoma, así como por la significación para las víctimas y sus familiares. Gracias a estos instrumentos normativos han podido ser preservados estos espacios memoriales, salvaguarda sin la cual ahora estarían en riesgo de desaparecer.

La aprobación de una norma con el mayor rango como fue la Ley 2/2017 manifestó de manera inequívoca el compromiso político para afianzar mayores garantías de preservación de la memoria. Una ley que no debería ser considerada como colofón, sino como un paso, decisivo y trascendental, pero que debe continuar siendo implementada con el necesario desarrollo reglamentario que facilite su aplicación. El ambicioso propósito y las innovaciones de dicha ley que han sido referencia en otras regulaciones autonómicas, deben acompañarse de una voluntad y un imprescindible impulso político acorde con una incontestable demanda ciudadana.

Está claro que la protección de los lugares es el primer pilar sobre el que se debe trabajar cuando hablamos de espacios de memoria asociados a hechos de un pasado trágico cada vez más lejano, pero esa tarea debe ser continuada con la difusión y el conocimiento público, aspectos fundamentales para la reparación de las víctimas. Asimismo, la finalidad de este texto persigue algo fundamental, ser abertura de nuevos debates y líneas de acción futuras, como por ejemplo el de una pedagogóía que convierta el conocimiento de los lugares en una garantía de no repetición de la barbarie. En esa labor las administraciones tienen una enorme responsabilidad que no puede quedarse en la mera declaración, es necesario establecer alianzas entre las instituciones públicas, las asociaciones y el ámbito educativo para abundar en esa tarea pedagógica que es el objetivo final que plantea en Andalucía la Ley de Memoria Histórica y Democrática. 
Los avances en el desarrollo de políticas públicas de memoria en los últimos años en Andalucía, sobre la base de un trabajo mancomunado de administraciones, colectivos memorialistas, universidades y otros centros de investigación, no sólo había favorecido unos resultados moderadamente satisfactorios, sino sobre todo había generado unas expectativas alentadoras para los familiares de las víctimas. Sin embargó, la situación política actual en Andalucía ha consolidado una realidad a día de hoy muy distinta para las políticas públicas de memoria en la comunidad andaluza, con una amenaza constante, claramente influenciada por el peso político de la ultraderecha en la estabilidad del actual Gobierno autonómico, sobre las iniciativas y actuaciones dirigidas a la protección de las víctimas de la Guerra Civil y la Posǵuerra en la región andaluza -y muy especialmente la derogación de la propia Ley de $2017^{54}$ - como de toda la estructura administrativa, centrada en la supresión de la Dirección General de Memoria Democrática ${ }^{55}$ y su conversión en Comisionado de la Concordia, fundamental para la cobertura diaria de las iniciativas memorialistas -lugares de memoria, fosas, investigaciones, etc. ${ }^{56}$ - paralizadas en el momento en que se redacta este texto.

Será únicamente el paso del tiempo y el análisis sosegado de investigaciones futuras los que permitan medir el verdadero alcance de este, a día de hoy innegable, proceso de paralización de las políticas públicas de memoria en Andalucía, y sus efectos, fundamentalmente sobre una ciudadanía demandante, cada vez más envejecida y desolada.

\section{Bibliografía}

Baquero, Juan Miguel, «Víznar-Alfacar: el barranco donde todos eran Lorea», El Diario, 30 de junio de 2013.

Baquero, Juan Miguel, «PP y Cs nombran el Comisionado para la Concordia que exige Vox "para reemplazar la Ley de Memoria Histórica”», El Diario.es, 2 de abril de 2020.

Bedmar, Arcángel, Baena roja y negra; Guerra Civil y represión (1936-1943), Lucena, Juan de Mairena y de libros, 2009.

Burgos, Rosa, Las muertes de García Caparrós, Málaga, Airon Sesenta, 2017.

${ }^{54}$ Rodríguez, 2020, https://www.elmundo.es/andalucia/2020/01/29/5e31dbc1fe6c8302138b459b. html [consultado el 06/08/2020].

${ }_{55}$ Baquero, 2020, https://www.eldiario.es/andalucia/pp-comisionado-concordia-memoria-historica_1_5918694.html [consultado el 06/08/2020].

${ }^{56}$ Europa Press, «La Coordinadora Andaluza de Memoria dice que "el Gobierno de las tres derechas está dejando morir la ley por inacción”», 18 de junio de 2020, https://www.europapress.es/andalucia/noticia-coordinadora-andaluza-memoria-dice-gobierno-tres-derechas-dejando-morir-leyinaccion-20190618135307.html [consultado el 06/08/2020]. 
Checa, Sandra, Ángel del Río, y Ricardo Martín, Andaluces en los campos de Mauthausen, Sevilla, Centro de Estudios Andaluces, 2006.

Cruz Artacho, Salvador, Autonomía y federalismo en el pensamiento y en la praxis política de Blas Infante, Sevilla, Fundación Centro de Estudios Andaluces, 2013.

Domínguez, Alicia, El verano que trajo un largo invierno: La represión político-social durante el primer Franquismo en Cádiz (1936-1945), Cádiz, Quorum libros, 2004.

Egea, Nieves, «Villa Maya, el derribo de la Memoria», Cadena Ser, 29 de marzo de 2019.

Fernández Albéndiz, Carmen, y F. Javier Giráldez Díaz, «La represión física en Andalucía», en Fernando Martínez y Miguel Gómez (coords.), La memoria de todos. Las heridas del pasado se curan con más verdad, Sevilla, Fundación Alfonso Perales, 2013, pp. 49-68.

Fernández Luceño, María Victoria, La ranilla: prisión de presos políticos del Franquismo, Sevilla, Aconcagua, 2018.

Fernández Martín, Andrés, 1937. Éxodo Málaga Almería: Nuevas fuentes de investigación, Málaga, Aratispi Ediciones, 2016.

García Bravo, Juan Carlos, «Un decenio de legislación de memoria histórica en España», Crónica Popular, 8 de diciembre de 2018.

García Márquez, José María, «El Centro del terror: la comisaría de la calle Jesús del Gran Poder», en Rafael López Fernández (coord.), Lugares de la Memoria: golpe militar, represión y resistencia en Sevilla, Sevilla, Aconcagua, 2014, pp. 145-149.

Gil Bracero, Rafael, y M. Isabel Brenes, Jaque a la República (Granada, 1936-1939), Armilla, Ediciones Osuna, 2009.

Giráldez Díaz, Francisco Javier, «Política y memoria en la historia reciente de Andalucía», Universidad de Sevilla, tesis doctoral inédita, 2014.

Giráldez Díaz, Francisco Javier, y Miguel Ángel Melero Vargas, «La pervivencia de la memoria. De la lucha contra el olvido a las actitudes de postresistencia al Franquismo en Andalucía», Contenciosa, 7, 2017, https://doi.orǵ/10.14409/contenciosa. v0i7.8580.

Gómez Oliver, Miguel, Fernando Martínez López y Antonio Barragán Moriana (coords.), El botín de guerra en Andalucía: cultura represiva y víctimas de la Ley de Responsabilidades Políticas, 1936-1945, Madrid, Biblioteca Nueva, 2015.

Junquera, Natalia, «La promesa que Rajoy sí cumplió», El País, 5 de octubre de 2013.

López Fernández, Rafael, Lugares de la Memoria: Golpe militar, represión y resistencia en Sevilla, Sevilla, Aconcagua, 2014.

Machado, Antonio, Campos de Castilla, Madrid, Cátedra, 2006.

Martínez López, Fernando (coord.), Los andaluces en el exilio del 39, Sevilla, Fundación Centro de Estudios Andaluces, 2014.

Mate, Reyes, La herencia del olvido, Madrid, Errata Nature, 2008.

Melero Vargas, Miguel Ángel, «La represión franquista sobre la resistencia guerrillera en Andalucía. Algunos datos para su mejor comprensión», en Fernando Martínez López y Miǵuel Gómez Oliver (coords.), La memoria de todos: las heridas del pasado se curan con más verdad, Sevilla, Fundación Alfonso Perales, 2014, pp.149-168. 
Melero Vargas, Miǵuel Ángel, «Actitudes poliédricas: nuevos enfoques sobre la respuesta ciudadana ante el Franquismo en sus primeros años», Pilar Folguera et al. (coords.), Pensar con la historia desde el siglo XXI: actas del XII Congreso de la Asociación de Historia Contemporánea, Madrid, Universidad Autónoma de Madrid, 2015, pp. 5753-5774.

Nora, Pierre, Les lieux de mémoire, París, Gallimard, 1984.

Ortiz Villalba, Juan, Del golpe militar a la Guerra Civil. Sevilla 1936, Sevilla, RD Editores, 2006.

Pantoja Vallejo, Antonio, y José Luis Pantoja Vallejo, La XIV Brigada Internacional en Andalucía. La tragedia de Villa del Río y la batalla de Lopera, Jaén, Diputación Provincial, 2006.

Rengel, Carmen, «Andalucía aprueba la pionera Ley de Memoria Democrática», Huffington Post, 19 de marzo de 2017.

Rodríguez, Chema, «Vox trata de marear la agenda del Gobierno PP-Cs con una Ley de Concordia para evitar "profanaciones"», El Mundo, 29 de enero de 2020.

Rodríguez Padilla, Eusebio, La represión franquista en Almería 1939-1945, Almería, Arráez editores, 2007.

Serrano, María, Lugares de Memoria de Andalucía, Sevilla, Consejería de Cultura de la Junta de Andalucía, 2017. 